\title{
Trade-offs between global warming and day length on the start of the carbon uptake period in seasonally cold ecosystems
}

\author{
Georg Wohlfahrt, ${ }^{1}$ Edoardo Cremonese, ${ }^{2}$ Albin Hammerle, ${ }^{1}$ Lukas Hörtnagl, ${ }^{1}$ \\ Marta Galvagno, ${ }^{2}$ Damiano Gianelle, ${ }^{3,4}$ Barbara Marcolla, ${ }^{3}$ and Umberto Morra di Cella ${ }^{2}$ \\ Received 1 October 2013; revised 12 November 2013; accepted 14 November 2013; published 12 December 2013.
}

[1] It is well established that warming leads to longer growing seasons in seasonally cold ecosystems. Whether this goes along with an increase in the net ecosystem carbon dioxide $\left(\mathrm{CO}_{2}\right)$ uptake is much more controversial. We studied the effects of warming on the start of the carbon uptake period (CUP) of three mountain grasslands situated along an elevational gradient in the Alps. To this end, we used a simple empirical model of the net ecosystem $\mathrm{CO}_{2}$ exchange, calibrated, and forced with multiyear empirical data from each site. We show that reductions in the quantity and duration of daylight associated with earlier snowmelts were responsible for diminishing returns, in terms of carbon gain, from longer growing seasons caused by reductions in daytime photosynthetic uptake and increases in nighttime losses of $\mathrm{CO}_{2}$. This effect was less pronounced at high, compared to low, elevations, where the start of the CUP occurred closer to the summer solstice when changes in day length and incident radiation are minimal. Citation: Wohlfahrt, G., E. Cremonese, A. Hammerle, L. Hörtnagl, M. Galvagno, D. Gianelle, B. Marcolla, and U. M. di Cella (2013), Trade-offs between global warming and day length on the start of the carbon uptake period in seasonally cold ecosystems, Geophys. Res. Lett., 40, 6136-6142, doi:10.1002/2013GL058182.

\section{Introduction}

[2] As global temperatures keep rising, plants in seasonally cold climates such as the temperate and boreal biomes of the Northern Hemisphere experience increasing growing season lengths. Convincing evidence for warming induced earlier spring plant activity and, although less prominent, delays in autumnal plant senescence derives from plant phenological observations and satellite remote sensing [Jeong et al., 2011; Myneni et al., 1997; Stöckli and Vidale, 2004]. Whether longer

Additional supporting information may be found in the online version of this article.

${ }^{1}$ Institute of Ecology, University of Innsbruck, Innsbruck, Austria

${ }^{2}$ Environmental Protection Agency of Aosta Valley, ARPA VdA, Climate Change Unit, Aosta, Italy.

${ }^{3}$ Sustainable Agro-Ecosystems and Bioresources Department, Research and Innovation Centre, Fondazione Edmund Mach, San Michele all'Adige, Italy.

${ }^{4}$ Foxlab, Research and Innovation Centre, Fondazione Edmund Mach, San Michele all'Adige, Italy.

Corresponding author: G. Wohlfahrt, Institute of Ecology, University of Innsbruck, 6020 Innsbruck, Austria. (georg.wohlfahrt@uibk.ac.at)

(C)2013 The Authors. Geophysical Research Letters published by Wiley on behalf of the American Geophysical Union.

This is an open access article under the terms of the Creative Commons Attribution-NonCommercial-NoDerivs License, which permits use and distribution in any medium, provided the original work is properly cited, the use is non-commercial and no modifications or adaptations are made. 0094-8276/13/10.1002/2013GL058182 growing seasons translate into longer carbon uptake periods (CUP), i.e., the time period during which the net ecosystem carbon dioxide $\left(\mathrm{CO}_{2}\right)$ exchange (NEE) is negative corresponding to the period of net carbon gain by ecosystems, however, is much more controversial. Published reports range from increased [Aurela et al., 2004; Churkina et al., 2005; Dragoni et al., 2011], over no change [Humphreys and Lafleur, 2011; Parmentier et al., 2011], to reduced net carbon gain or even net carbon release with increasing growing season length [Angert et al., 2005; Galvagno et al., 2013; Hu et al., 2010; Piao et al., 2008; Randerson et al., 1999].

[3] One aspect that has not been formerly investigated is the degree to which shorter day length and lower levels of incident radiation during earlier starts/later ends of the growing season may limit the potential for additional carbon gains. From first principles, it is to be expected that daily net carbon gains will be more difficult to realize during these times due to shorter daylight periods, during which plants may assimilate $\mathrm{CO}_{2}$, combined with lower levels of incident radiation and correspondingly longer nighttime periods, during which ecosystems release $\mathrm{CO}_{2}$ through respiration.

[4] The objective of the present paper is thus to investigate the trade-offs between shorter day lengths, lower levels of incident radiation, and warming induced earlier starts of the growing season on the start of the CUP. To this end, we investigate three mountain grassland ecosystems in the Alps ranging in elevation from 970 to 2160 meters above sea level ( $\mathrm{m}$ asl), providing a gradient in the timing of spring snowmelt and thus the start of the growing period.

[5] We hypothesize (Hypothesis 1) that shorter day lengths/ lower levels of incident radiation at the beginning of the growing season, associated with warming induced earlier snowmelt, reduce the carbon gain that can be realized with the lengthening of the snow-free period. Furthermore, we hypothesize (Hypothesis 2) that this effect is more pronounced at lower elevations, where snowmelt occurs around the spring equinox when day length changes most rapidly. Conversely, at higher elevations, where snowmelt occurs closer to the summer solstice when changes in day length are minimal, we expect relatively modest effects. In order to disentangle the effects of day length and incident radiation from confounding year-to-year variability in environmental conditions, we use a simple empirical model, which we calibrate and force with multiyear records of ecosystem-atmosphere NEE measurements and environmental drivers, respectively.

\section{Methodology}

\subsection{Experimental Data}

[6] This study makes use of multiyear records of NEE, measured by means of the eddy covariance method [Aubinet et al., 
Table 1. Characteristics of the Three Investigated Mountain Grassland Sites

\begin{tabular}{lccc}
\hline Site & Neustift & Monte Bondone & Torgnon \\
\hline Country & Austria & Italy & Italy \\
Latitude & $47^{\circ} 07^{\prime} \mathrm{N}$ & $46^{\circ} 01^{\prime} \mathrm{N}$ & $45^{\circ} 50^{\prime} \mathrm{N}$ \\
Longitude & $11^{\circ} 19^{\prime} \mathrm{E}$ & $11^{\circ} 02^{\prime} \mathrm{E}$ & $7^{\circ} 34^{\prime} \mathrm{E}$ \\
$\begin{array}{l}\text { Elevation } \\
\quad(\text { masl })\end{array}$ & 970 & 1550 & 2160 \\
MAT $\left({ }^{\circ} \mathrm{C}\right)^{\mathrm{a}}$ & & & \\
MAP $(\mathrm{mm})^{\mathrm{b}}$ & 6.5 & 5.5 & 3.1 \\
Snowmelt & $70(49-91)$ & $115(87-129)$ & $128(102-144)^{\mathrm{d}}$ \\
$\quad$ date $^{\mathrm{c}}$ & & & \\
Management & Intensive meadow & Extensive meadow & None \\
Data coverage & $2001-2011$ & $2003-2009$ & $2009-2011$ \\
Key reference & Wohlfahrt et al. & Marcolla et al. & Galvagno et al. \\
& {$[2008 \mathrm{a}]$} & {$[2011]$} & {$[2013]$} \\
\hline
\end{tabular}

\footnotetext{
aThe mean annual temperature.

${ }^{\mathrm{b}}$ The mean annual precipitation.

${ }^{\mathrm{c}}$ The median and observed range in Julian date.

${ }^{\mathrm{d}}$ Based on data from 2000 to 2011.
}

2000; Baldocchi et al., 1988], at three mountain grassland study sites in the Alps, Neustift, Monte Bondone, and Torgnon (Table 1). For details on the study sites, the measurements of NEE and associated environmental parameters, we refer to the key site references listed in Table 1 and Peichl et al. [2013]. The timing of snowmelt was determined from automated/manual snow height measurements, the analysis of webcam images [Migliavacca et al., 2011a], measurements of albedo, and/or soil temperature [Hammerle et al., 2008]. The start of the CUP was defined as the date in spring when the 5 day daily moving average NEE turned to net uptake $(\mathrm{NEE}<0)$ [Galvagno et al., 2013].

\subsection{Modeling}

[7] Daily average NEE $\left(\mu \mathrm{mol} \mathrm{m} \mathrm{m}^{-2} \mathrm{~s}^{-1}\right)$ was calculated as

$$
\begin{aligned}
\mathrm{NEE} & =\frac{\mathrm{NEE}_{d} t_{d}+\mathrm{NEE}_{n}\left(24-t_{d}\right)}{24} \\
& =\frac{\left(A+R_{d}\right) t_{d}+R_{n}\left(24-t_{d}\right)}{24} \sim \frac{A t_{d}}{24}+R,
\end{aligned}
$$

where the subscript $d$ stands for daytime, $n$ for nighttime, and $t_{d}$ is the day length (hours), which was calculated according to Campbell and Norman [1998], with the civil twilight parameter adjusted at each site to provide the best fit to measured day length (defined as the time period with incident photosynthetically active radiation $>5 \mu \mathrm{mol}$ photons $\mathrm{m}^{-2} \mathrm{~s}^{-1}$ ) (Figure $\mathrm{S} 1$ in the supporting information). Average daytime NEE was then further split into gross photosynthesis $\left(A ; \mu \mathrm{mol} \mathrm{m}{ }^{-2} \mathrm{~s}^{-1}\right)$ and daytime ecosystem respiration $\left(R_{d}\right.$; $\left.\mu \mathrm{mol} \mathrm{m} \mathrm{m}^{-2} \mathrm{~s}^{-1}\right)$, while average nighttime NEE was equated with average ecosystem nighttime respiration $\left(R_{n} ; \mu \mathrm{mol}\right.$ $\mathrm{m}^{-2} \mathrm{~s}^{-1}$ ). Finally, we assumed that $R_{d}=R_{n}$, i.e., ecosystem respiration is the same during day and night and replaced $R_{d}$ and $R_{n}$ by daily average ecosystem respiration $(R ; \mu \mathrm{mol}$ $\left.\mathrm{m}^{-2} \mathrm{~s}^{-1}\right)$. Tests with separate formulations of daytime and nighttime ecosystem respiration based on corresponding temperatures showed that use of an average daily ecosystem respiration does not reduce model performance. Due to the fact that the model is run over a relatively short period of time ( $<50$ days) during which soil moisture, due to the preceding snowmelt, is relatively high, the respiration model does not include a moisture term, which would be required for seasonal simulations and more variable soil moisture conditions [e.g., Migliavacca et al., 2011b].

[8] Daily average gross photosynthesis was modeled as a Michaelis-Menten-type function of daily average incident photosynthetically active radiation $\left(I ; \mu\right.$ mol photons $\left.\mathrm{m}^{-2} \mathrm{~s}^{-1}\right)$, modified by a Gompertz-type phenological scalar based on the sum of daily average air temperature $\left(T ;{ }^{\circ} \mathrm{C}\right)>0{ }^{\circ} \mathrm{C}$ since snowmelt $\left(T^{*} ;{ }^{\circ} \mathrm{C}\right)$

$$
A=-\frac{\mathrm{a} I}{\mathrm{~b}+I} \exp \left[\mathrm{c} \exp \left(\mathrm{d} T^{*}\right)\right]
$$

[9] Snowmelt was simulated to occur when the sum of air temperature, cumulated since 1 January for $T>0^{\circ} \mathrm{C}$, crossed a site-specific threshold, $T_{\text {crit }}^{\text {snow }}\left({ }^{\circ} \mathrm{C}\right)$.

[10] Daily average ecosystem respiration was simulated as an exponential function of $T$ modified by a phenological scalar linearly dependent on $T^{*}$ [Wohlfahrt et al., 2008a].

$$
R=\left(\mathrm{e} T^{*}+\mathrm{f}\right) \exp (\mathrm{g} T)
$$

[11] The phenological scalars are supposed to capture temporal changes in amount and photosynthetic activity of the plant leaf area and correlated changes in belowground respiratory activity.

[12] Free model parameters a-g were determined by minimizing the sum of the absolute differences between measured and simulated daytime and nighttime average NEE, weighted by the respective random uncertainties [Richardson and Hollinger, 2005], while $T_{\text {crit }}^{\text {snow }}$ was determined by simple least squares regression (Table $\mathrm{S} 1$ ).

[13] In order to disentangle the effects of day length and incident radiation from confounding year-to-year variability in environmental conditions, simulations of warming were conducted with climatologies of incident photosynthetically active radiation and air temperature, derived as detailed in the supporting information. Incident photosynthetically active radiation was kept at the values of the climatologies, while warming was simulated by uniformly increasing climatological air temperatures up to $+3 \mathrm{~K}$ in $0.25 \mathrm{~K}$ steps. The upper value of $+3 \mathrm{~K}$ was chosen as it is in the middle of the range of projections of regional climate models for the end of this century [Gobiet et al., 2013; Smiatek et al., 2009].

[14] In principle, the same mechanisms investigated for the start of the CUP in spring might be expected to be at work at the end of the CUP in autumn. Initially, the same model as above, with the phenological scalar in equations (2) and (3) modified to simulate a reduction in gross photosynthesis and ecosystem respiration with decreasing temperature, was thus used to simulate NEE during the autumn transition from carbon sink to source (data not shown). Due to carry-over effects from the last managed intervention (Figure 1) and due to the fact the downregulation of plant carbon gain during autumn appears to be a more complicated process than the upregulation in spring [Richardson et al., 2013], the model performed poorly at the end of the CUP, which is why in the present paper we focus on start of the CUP only.

\section{Results}

[15] Snowmelt was time delayed with increasing elevation and occurred between day of year (DOY) 49-91, 87-129, and 102-144 at Neustift, Monte Bondone, and Torgnon, respectively (Table 1). The simple snowmelt model, driven 

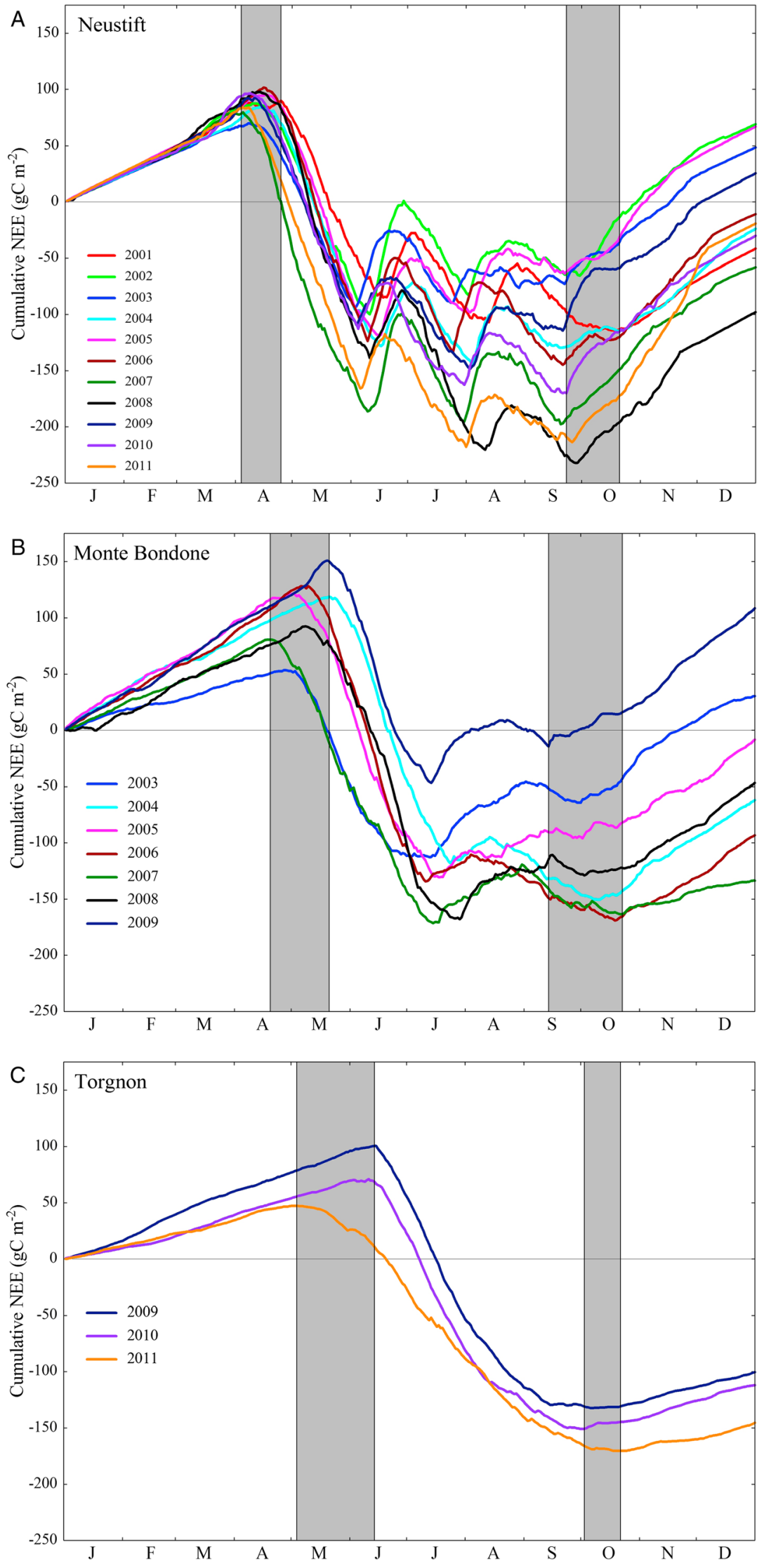

Figure 1. Cumulative net ecosystem $\mathrm{CO}_{2}$ exchange (NEE) at the study sites Neustift, Monte Bondone, and Torgnon. Grey areas indicate the range in the start and end of the carbon uptake period (CUP). Sudden upward trends in cumulative NEE during the CUP at Neustift and Monte Bondone correspond to times when the grasslands were harvested, which caused them to temporarily turn into carbon sources [Marcolla et al., 2011; Wohlfahrt et al., 2008a; Wohlfahrt et al., 2008b]. 

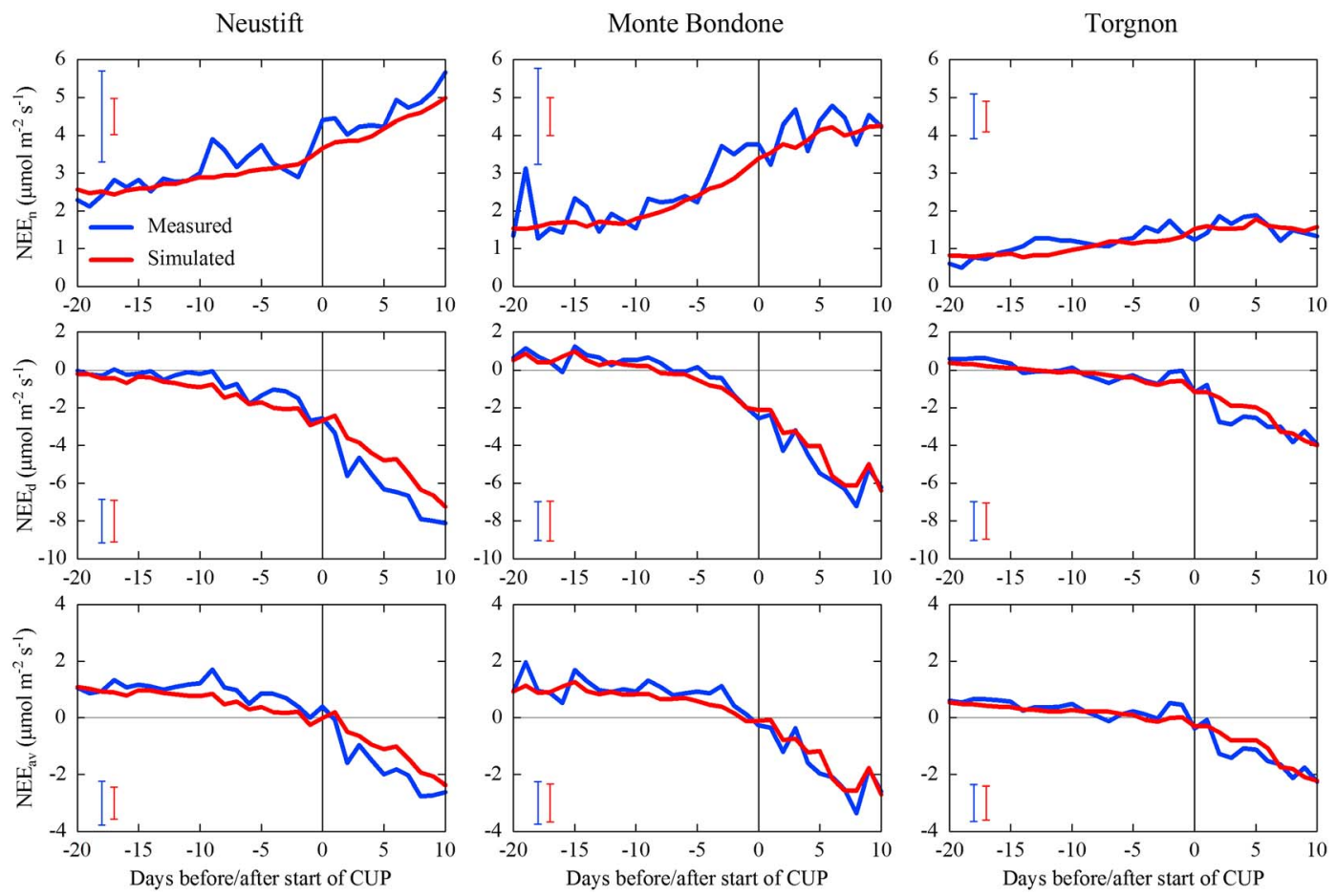

Figure 2. Measured and simulated multiyear average (top) nighttime, (middle) daytime and (bottom) daily average net ecosystem $\mathrm{CO}_{2}$ exchange (NEE) at the study sites Neustift, Monte Bondone, and Torgnon. Data are binned by day before/after the start of the carbon uptake period (CUP). Error bars represent multiyear average standard deviations of measured and simulated NEE.
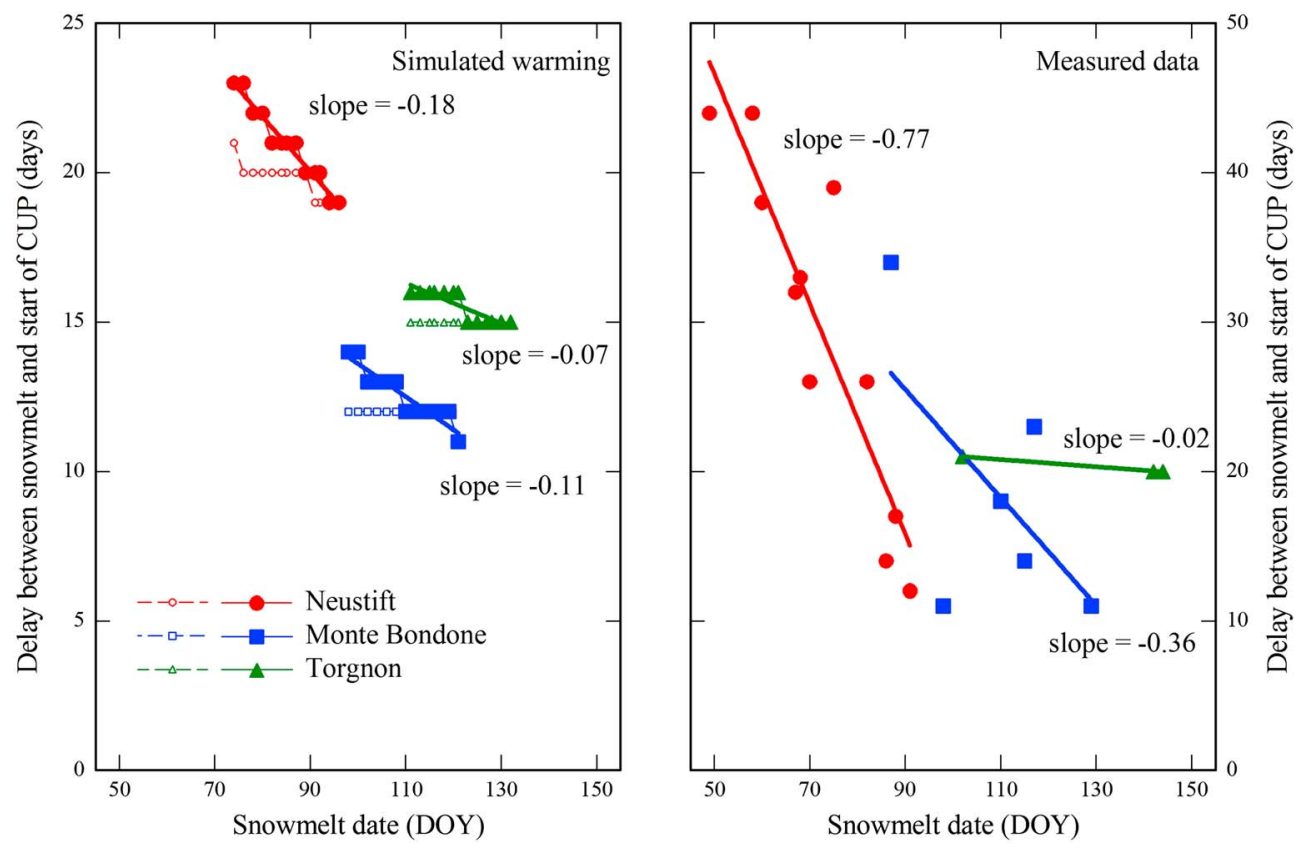

Figure 3. Time delay between snowmelt date and the start of the carbon uptake period (CUP) based on simulated warming using (left) climatological drivers and (right) as measured during the study period. Warming in the Figure 3 (left) was simulated by uniformly increasing climatological temperature (rightmost data points) up to $+3 \mathrm{~K}$ (leftmost data points) in $0.25 \mathrm{~K}$ steps (closed symbols); lines and slope values represent linear fits to these data. The stepwise pattern in Figure 3 (left) results from changes in NEE in response to $0.25 \mathrm{~K}$ warming steps that do not cause daily NEE to switch sign. Open symbols in Figure 3 (left) refer to warming simulations where day length and incident radiation were increased to the values of the control simulation, as explained in the text. Lines and slope values in Figure 3 (right) refer to linear fits to the measured data with $R^{2}$ values of 0.82, 0.37, and 0.99 at Neustift, Monte Bondone, and Torgnon, respectively. Note on the different scales of the $y$ axis in Figure 3 (right). 
solely by cumulated air temperature, predicted snowmelt dates with a $0.5<R^{2}<0.8$ and a mean absolute error (MAE) $4.8<$ MAE $<8.2$ days (Table S2). The start of the CUP followed the elevational gradient in the timing of snowmelt and occurred between DOY 93-114, 109-140, and 123-164 at Neustift, Monte Bondone, and Torgnon, respectively (Figure 1). Daily changes in day length at the start of the CUP were inversely related to the start of the CUP, a 10 day earlier onset of the CUP amounting to a 32, 27, and $20 \mathrm{~min}$ reduction in day length at Neustift, Monte Bondone, and Torgnon, respectively.

[16] The calibrated model was well able to capture the temporal course in average daytime $\left(0.69<R^{2}<0.79,0.65\right.$ $<$ MAE $\left.<1.12 \mu \mathrm{mol} \mathrm{m}^{-2} \mathrm{~s}^{-1}\right)$ and nighttime $\left(0.42<R^{2}\right.$ $\left.<0.64,0.31<\mathrm{MAE}<0.88 \mu \mathrm{mol} \mathrm{m}^{-2} \mathrm{~s}^{-1}\right)$ NEE after snowmelt (Table S2), even though observed interannual variability in nighttime NEE was underestimated (Figure 2). Nevertheless, the model accurately reproduced daily average NEE and the start of the CUP (to within 2 days or less) (Figure 2).

[17] Simulated warming caused both the snowmelt date and the start of the CUP to advance, the latter however lagged the former and thus the time period and integrated carbon losses in between increased with simulated warming (Figure 3 ). A simulated 10 day earlier snowmelt caused the time period until the start of the CUP to extend by $1.8,1.1$, and 0.7 days (Figure 3 ) and increased carbon losses by $2.8,1.2$, and $0.4 \mathrm{gC} \mathrm{m}^{-2}$ (data not shown) at Neustift, Monte Bondone, and Torgnon, respectively. The delay, in absolute terms, was longest at Neustift, followed by Torgnon and Monte Bondone, reflecting sitespecific differences (represented in the model parameters; Table S1) in the ecosystem's ability to recover net ecosystem carbon gain after snowmelt.

[18] As simulated warming affects NEE not only indirectly through advancements in the snowmelt date and associated changes in day length and incident radiation but also directly through equations (2) and (3), we ran a second set of warming simulations with day length and incident radiation increased so that each day these would take the same values as in the control simulation based (i.e., $+0 \mathrm{~K}$ warming on the climatological data). Controlling for day length and incident radiation in this way largely removed the lengthening of the period between snowmelt date and start of the CUP (Figure 3 ) and the associated $\mathrm{CO}_{2}$ losses (data not shown), confirming the importance of day length and incident radiation in shaping the observed response to warming.

[19] Measured interannual variations in the delay between snowmelt and the start of the CUP confirmed the trend of the warming simulations, i.e., earlier snowmelts caused the time period until the start of the CUP to increase also under realworld conditions (Figure 3). However, compared to the simulated warming imposed on the temperature climatologies, the magnitude of change was, with the exception of Torgnon where only 3 years of measurements were available, 3 to 4 times larger. In addition, interannual variations were, at least partly (e.g., Monte Bondone), characterized by considerable scatter, with similar snowmelt dates resulting in delays until the start of the CUP that differed by more than 20 days (Figure 3 ).

\section{Discussion}

[20] While earlier/delayed plant activity in spring/autumn and their negative/positive correlation with warming are well documented for the Northern Hemisphere [Jeong et al., 2011; Menzel et al., 2006; Myneni et al., 1997; Schwartz et al., 2006; Stöckli and Vidale, 2004], reports on the resulting effects on the NEE of terrestrial ecosystems are contradictory [Piao et al., 2007; Richardson et al., 2013]. In the present paper the role of reductions in day length and incident radiation going along with advancements in the growing season start for any additional carbon gain that may be realized during this period was investigated.

[21] We hypothesized (Hypothesis 1) that there should be diminishing returns, in terms of carbon gain, of earlier snowmelts, as solar geometry reduces the quantity and duration of daylight early in the season, and thus daytime plant photosynthetic $\mathrm{CO}_{2}$ uptake, and conversely increases the length of the nighttime period, during which respiration dominates and ecosystems act as sources for $\mathrm{CO}_{2}$. Consistent with Hypothesis 1, we found that simulated warming caused the time period between snowmelt and the start of the CUP, during which ecosystems act as source of $\mathrm{CO}_{2}$, to increase, which could be shown to be due to combined reductions in day length and incident radiation (Figure 3). In accordance with other experimental studies [Galvagno et al., 2013; Merbold et al., 2012; Migliavacca et al., 2011a; Wohlfahrt et al., 2008a], longer periods of $\mathrm{CO}_{2}$ losses following earlier snowmelt were also observed on the basis of the actual interannual variability in snowmelt and start of the CUP dates (Figure 3). Except for Torgnon, where only 3 years of data were available, the sensitivity of the start of the CUP to changes in snowmelt dates was however 3 to 4 times larger under naturally varying weather conditions, compared to the simulated warming experiment (Figure 3). It thus appears that interannual variations in the depth of the snowpack and environmental conditions after its melt act as to amplify the effects of day length and incident radiation. In particular, it was observed that daytime NEE after earlier snowmelts, which were associated with less than average (compared to the climatology) incident radiation, required more time to become negative or oscillated between net source and sink.

[22] These confounding effects are also key to reconciling our results with experimental studies [e.g., Aurela et al., 2004], which report larger carbon gains following earlier snowmelts. With one exception discussed below, shorter day lengths and lower levels of incident radiation associated with earlier snowmelts should per se always cause a reduction in NEE and thus a lengthening of the period between snowmelt and the start of the CUP. Reported constant or larger carbon gains following earlier snowmelts are thus likely to result from confounding environmental effects, e.g., earlier snowmelts being associated with environmental conditions that promote ecosystem carbon gain or reduce ecosystem respiration, which compensate for the effects of reduced day length and incident radiation. As discussed by Parmentier et al. [2011], these effects are likely to be site specific. For example, Humphreys and Lafleur [2011] found that temperature-driven earlier snowmelts at two nearby tundra sites caused diverging patterns in NEE after snowmelt: A fen site responded with increased NEE, while a mixed tundra site showed no response or even a decrease in NEE in response to earlier snowmelts.

[23] The exception to this general rule are sites which are located far enough north [e.g., Aurela et al., 2004] or at high elevation [e.g., Beniston et al., 2003] so that snowmelt and the start of the CUP occur after the summer solstice. In these cases, any advancement in snowmelt date, through an 
increase in day length and incident radiation, will per se always have a positive effect on the NEE.

[24] Taken together, the demonstrated diminishing returns of earlier starts of the growing season (i.e., snowmelt date) sound a note of caution to simple extrapolation of experimentally observed additional carbon gains during longer growing seasons $\left(2-18 \mathrm{gC} \mathrm{m}^{-2} \mathrm{y}^{-1}\right.$ for each additional day of CUP) [Aurela et al., 2004; Churkina et al., 2005; Dragoni et al., 2011; Wu et al., 2012] into the future, as these extrapolations are likely to be biased high.

[25] Consistent with our Hypothesis 2, we found that the diminishing returns in terms of carbon gain of any advancements of the growing season on the start of the CUP were more pronounced at lower elevations, where snowmelt occurred around the spring equinox, as opposed to higher elevations, where snowmelt occurred closer to the summer solstice. Around the spring equinox, day length and incident radiation change most rapidly, and thus, any advancement in the timing of snowmelt and the CUP is more heavily "penalized" compared to sites where snowmelt and the start of the CUP occur closer to the summer solstice, around which changes in day length and incident radiation are minimal, or even after the summer solstice, when earlier snowmelt causes an increase in day length and incident radiation. It can thus be concluded that ecosystems at higher elevations will be better able to take advantage from warming induced longer growing seasons in terms of carbon gain than ecosystems at lower elevations.

[26] The present study made use of gradient in the timing of snowmelt driven by the reduction of temperature with increasing elevation [Körner, 2007], our conclusions are however expected to be more universally valid and thus hold for example also for gradients in growing season length driven by latitude, even though Wu et al. [2012] caution that different ecosystem types may show a contrasting response.

[27] Acknowledgments. The research leading to these results has received partial funding from the Austrian Ministry for Science and Research within the program Sparkling Science (SPA/03-112/GrassClim), the European Community's Fifth and Seventh Framework Program under grant agreements EVK2-CT2001-00125 and 244122, the Austrian National Science Fund (FWF) under grant agreements P17560-B03, P19849-B16, and P23267-B16, and the Tyrolean Science Fund under grant agreements UNI-404-33, UNI-404-486, and UNI-404-1083. Research at the site Monte Bondone was supported by EU project GHG Europe (EU contract 244122) and the CARBOITALY project funded by the Italian government. Activities at the Torgnon study site were supported by PhenoAlp and ePheno, and Interreg projects cofunded by the European Regional Developmental Fund, under the operational program for cross-border cooperation Italy-France (ALCOTRA) 2007-2013.

[28] The Editor thanks two anonymous reviewers for their assistance in evaluating this paper.

\section{References}

Angert, A., S. Biraud, C. Bonfils, C. C. Henning, W. Buermann, J. Pinzon, C. J. Tucker, and I. Fung (2005), Drier summers cancel out the $\mathrm{CO}_{2}$ uptake enhancement induced by warmer springs, Proc. Natl. Acad. Sci. U. S. A., 102(31), 10,823-10,827, doi:10.1073/pnas.0501647102.

Aubinet, M., et al. (2000), Estimates of the annual net carbon and water exchange of forests: The EUROFLUX methodology, Adv. Ecol. Res., 30, 113-175, doi:10.1016/s0065-2504(08)60018-5.

Aurela, M., T. Laurila, and J.-P. Tuovinen (2004), The timing of snow melt controls the annual $\mathrm{CO}_{2}$ balance in a subarctic fen, Geophys. Res. Lett., 31 , L16119, doi:10.1029/2004g1020315.

Baldocchi, D. D., B. B. Hincks, and T. P. Meyers (1988), Measuring biosphereatmosphere exchanges of biologically related gases with micrometeorological methods, Ecology, 69(5), 1331-1340, doi:10.2307/1941631.

Beniston, M., F. Keller, and S. Goyette (2003), Snow pack in the Swiss Alps under changing climatic conditions: An empirical approach for climate impacts studies, Theor. Appl. Climatol., 74(1-2), 19-31, doi:10.1007/ s00704-002-0709-1.

Campbell, G. S., and J. M. Norman (1998), An Introduction to Environmental Biophysics, 2nd ed., pp. 286, Springer, New York.

Churkina, G., D. Schimel, B. H. Braswell, and X. Xiao (2005), Spatial analysis of growing season length control over net ecosystem exchange, Global Change Biol., 11(10), 1777-1787, doi:10.1111/j.13652486.2005.001012.x.

Dragoni, D., H. P. Schmid, C. A. Wayson, H. Potter, C. S. B. Grimmond, and J. C. Randolph (2011), Evidence of increased net ecosystem productivity associated with a longer vegetated season in a deciduous forest in southcentral Indiana, USA, Global Change Biol., 17(2), 886-897, doi:10.1111/ j.1365-2486.2010.02281.x.

Galvagno, M., et al. (2013), Phenology and carbon dioxide source/sink strength of a subalpine grassland in response to an exceptionally short snow season, Environ. Res. Lett., 8(2), 025008, doi:10.1088/1748-9326/ $8 / 2 / 025008$.

Gobiet, A., S. Kotlarski, M. Beniston, G. Heinrich, J. Rajczak, and M. Stoffel (2013), 21st century climate change in the European Alps-A review, Sci. Total Environ., doi:10.1016/j.scitotenv.2013.07.050, in press.

Hammerle, A., A. Haslwanter, U. Tappeiner, A. Cernusca, and G. Wohlfahrt (2008), Leaf area controls on energy partitioning of a temperate mountain grassland, Biogeosciences, 5(2), 421-431, doi:10.5194/bg-5-421-2008.

Hu, J. I. A., D. J. P. Moore, S. P. Burns, and R. K. Monson (2010), Longer growing seasons lead to less carbon sequestration by a subalpine forest, Global Change Biol., 16(2), 771-783, doi:10.1111/j.1365-2486.2009.01967.x.

Humphreys, E. R., and P. M. Lafleur (2011), Does earlier snowmelt lead to greater $\mathrm{CO} 2$ sequestration in two low Arctic tundra ecosystems?, Geophys. Res. Lett., 38, L09703, doi:10.1029/2011GL047339.

Jeong, S.-J., C.-H. Ho, H.-J. Gim, and M. E. Brown (2011), Phenology shifts at start vs. end of growing season in temperate vegetation over the Northern Hemisphere for the period 1982-2008, Global Change Biol., 17(7), 2385-2399, doi:10.1111/j.1365-2486.2011.02397.x.

Körner, C. (2007), The use of "altitude" in ecological research, Trends Ecol. Evol., 22(11), 569-574, doi:10.1016/j.tree.2007.09.006.

Marcolla, B., A. Cescatti, G. Manca, R. Zorer, M. Cavagna, A. Fiora, D. Gianelle, M. Rodeghiero, M. Sottocornola, and R. Zampedri (2011), Climatic controls and ecosystem responses drive the inter-annual variability of the net ecosystem exchange of an alpine meadow, Agric. For. Meteorol., 151(9), 1233-1243, doi:10.1016/j.agrformet.2011.04.015.

Menzel, A., et al. (2006), European phenological response to climate change matches the warming pattern, Global Change Biol., 12(10), 1969-1976, doi:10.1111/j.1365-2486.2006.01193.x.

Merbold, L., N. Rogiers, and W. Eugster (2012), Winter $\mathrm{CO}_{2}$ fluxes in a subalpine grassland in relation to snow cover, radiation and temperature, Biogeochemistry, 111(1-3), 287-302, doi:10.1007/s10533-011-9647-2.

Migliavacca, M., et al. (2011a), Using digital repeat photography and eddy covariance data to model grassland phenology and photosynthetic $\mathrm{CO}_{2}$ uptake, Agric. For. Meteorol., 151(10), 1325-1337, doi:10.1016/j. agrformet.2011.05.012.

Migliavacca, M., et al. (2011b), Semiempirical modeling of abiotic and biotic factors controlling ecosystem respiration across eddy covariance sites, Global Change Biol., 17(1), 390-409, doi:10.1111/j.13652486.2010.02243.x.

Myneni, R. B., C. D. Keeling, C. J. Tucker, G. Asrar, and R. R. Nemani (1997), Increased plant growth in the northern high latitudes from 1981 to 1991, Nature, 3866(6626), 698-702, doi:10.1038/386698a0.

Parmentier, F. J. W., M. K. van der Molen, J. van Huissteden, S. A. Karsanaev, A. V. Kononov, D. A. Suzdalov, T. C. Maximov, and A. J. Dolman (2011), Longer growing seasons do not increase net carbon uptake in the northeastern Siberian tundra, J. Geophys. Res., 116(G4), G04013, doi:10.1029/ 2011 jg001653.

Peichl, M., et al. (2013), Convergence of potential net ecosystem production among contrasting C3 grasslands, Ecol. Lett., 16(4), 502-512, doi:10.1111/ ele. 12075.

Piao, S., P. Friedlingstein, P. Ciais, N. Viovy, and J. Demarty (2007), Growing season extension and its impact on terrestrial carbon cycle in the Northern Hemisphere over the past 2 decades, Global Biogeochem. Cycles, 21, GB3018, doi:10.1029/2006gb002888.

Piao, S., et al. (2008), Net carbon dioxide losses of northern ecosystems in response to autumn warming, Nature, 451(7174), 49-52, doi:10.1038/ nature 06444.

Randerson, J. T., C. B. Field, I. Y. Fung, and P. P. Tans (1999), Increases in early season ecosystem uptake explain recent changes in the seasonal cycle of atmospheric $\mathrm{CO}_{2}$ at high northern latitudes, Geophys. Res. Lett., 26(17), 2765-2768, doi:10.1029/1999g1900500.

Richardson, A. D., and D. Y. Hollinger (2005), Statistical modeling of ecosystem respiration using eddy covariance data: Maximum likelihood parameter estimation, and Monte Carlo simulation of model and parameter uncertainty, applied to three simple models, Agric. For. Meteorol., 131(3-4), 191-208, doi:10.1016/j.agrformet.2005.05.008. 
Richardson, A. D., T. F. Keenan, M. Migliavacca, Y. Ryu, O. Sonnentag, and M. Toomey (2013), Climate change, phenology, and phenological control of vegetation feedbacks to the climate system, Agric. For Meteorol., 169, 156-173, doi:10.1016/j.agrformet.2012.09.012.

Schwartz, M. D., R. Ahas, and A. Aasa (2006), Onset of spring starting earlier across the Northern Hemisphere, Global Change Biol., 12(2), 343-351, doi:10.1111/j.1365-2486.2005.01097.x.

Smiatek, G., H. Kunstmann, R. Knoche, and A. Marx (2009), Precipitation and temperature statistics in high-resolution regional climate models: Evaluation for the European Alps, J. Geophys. Res., 114, D19107, doi:10.1029/2008jd011353.

Stöckli, R., and P. L. Vidale (2004), European plant phenology and climate as seen in a 20-year AVHRR land-surface parameter dataset, Int. J. Remote Sens., 25(17), 3303-3330, doi:10.1080/01431160310001618149.
Wohlfahrt, G., A. Hammerle, A. Haslwanter, M. Bahn, U. Tappeiner, and A. Cernusca (2008a), Seasonal and inter-annual variability of the net ecosystem $\mathrm{CO}_{2}$ exchange of a temperate mountain grassland: Effects of weather and management, J. Geophys. Res., 113, D08110, doi:10.1029/ $2007 \mathrm{jd} 009286$.

Wohlfahrt, G., et al. (2008b), Biotic, abiotic, and management controls on the net ecosystem $\mathrm{CO}_{2}$ exchange of European mountain grassland ecosystems, Ecosystems, 11(8), 1338-1351, doi:10.1007/s10021-0089196-2.

Wu, C., et al. (2012), Interannual and spatial impacts of phenological transitions, growing season length, and spring and autumn temperatures on carbon sequestration: A North America flux data synthesis, Global Planet. Change, 92-93(0), 179-190, doi:10.1016/j. gloplacha.2012.05.021. 